\title{
EAP COURSE DESIGN WITHIN A CONTEXT OF INSTITUTIONAL CHANGE AND CROSS-DISCIPLINARY COLLABORATION: FACTORS SHAPING THE CREATING OF 'WRITING FOR COMMERCE'
}

Fiona Jackson

University of KwaZulu-Natal

\begin{abstract}
Many reports of needs analysis and curriculum design of EAP courses focus largely on the immediate pedagogic context and ensuing decision making and materials design processes of the course designers. This paper explores the process of curriculum design from the perspectives of both debates and developments within the field of language and literacy education, and the impact of international, national and institutional shifts in higher education on one course design process within one South African university. The paper explores the realities of institutional and disciplinary histories and changes that impacted on the design of an EAP course for a linguistically, culturally and racially diverse group of firstyear commerce students. The intricacies of creating such a course as an inter-disciplinary school, rather than departmental, project are explored and briefly evaluated. The key principles underpinning the course design are explained. The paper concludes with consideration of why the collaborative inter-disciplinary project has faded, although the course has continued successfully.
\end{abstract}

This paper traces the curriculum design process of Writing for Commerce (WC), a compulsory English for Academic Purposes (EAP) writing course for all first-year Commerce Students at the former University of Natal, Pietermartizburg (UN), first offered in 2001. My argument is framed in terms of shifts and debates within the field of language and writing instruction. I outline contextual factors, at national, institutional and disciplinary levels, that impacted on the course design process. A unique dimension to this project was its location within collaboration across two departments, and the relative successes and failures of this aspect are also considered. I outline the key principles informing the course structure and briefly consider the success and fragility of the cross-disciplinary course design process. I have drawn my data from interviews with three stakeholders ${ }^{1}$ and my observations as a participant researcher who was part of the design and teaching team.

\section{BRIEF OVERVIEW OF PEDAGOGIC/INSTRUCTIONAL DEBATES ON ACADEMIC LANGUAGE AND LITERACY DEVELOPMENT}

The field of academic development and, more specifically, academic literacy studies, has undergone significant shifts over the last twenty years. The key trajectory has been one of a move from focusing on the language deficits of students, which primarily presume grammatical remediation (Celce-Murcia, 1991), sometimes identified in the South African context as an English Second Language (ESL) approach, to a focus on the multiplicity and 
specificity of academic discourses that students are required to enter and master. This latter view, often identified as an Academic Literacies (AL) approach, shifts more responsibility onto institutions and lecturers to provide overt instruction on the underpinning values and conventions of their disciplines, as well as ongoing discipline-based literacy support for students throughout their degree courses (McKenna, 2004).

The former tradition is often deeply entrenched, particularly with respect to English Additional Language (EAL) students, in the minds of school teachers, students and content lecturers at universities. This partly stems from the 2500-year legacy of the equation of second/additional language teaching with the teaching of grammar (Celce-Murcia, 1991:459). Thus, for many discipline-based lecturers, the problems of students who communicate ineffectively in their academic writing primarily are seen to be problems of inadequate mastery of the grammatical constructions of formal English. Courses focusing strongly on intensive grammatical instruction by language experts operating independently from content lecturers thus is often seen to be the remedy.

However, ongoing psycholinguistic and sociolinguist research into language learning processes and the nature of communication within diverse academic communities has generated different understandings of how best to develop the academic reading and writing competencies of tertiary students. These approaches have drawn on insights from various sources, such as anthropological linguistics (Hymes, 1972); functional linguistics (Halliday, 1994); social theories of learning (Lave \& Wenger, 1991; Wenger, 1998); genre studies (Swales, 1990); and the New Literacy Studies (Street, 1995; Gee, 1990; Lea, 2005). McKenna identifies the key subsequent models of tertiary language intervention as English for Academic Purposes (EAP), and finally, Academic Literacies. She argues that the EAP focus has tended to construct learners as under prepared, and to focus on generic skills development in terms of general reading and writing strategies, with limited discipline-specific materials. The more recent AL orientation sees students as novices needing initiation into a range of academic subcultures. The assumption then is that students will gain most AL success through instruction that is deeply integrated within content courses (2004:67; Jacobs, 2005).

Despite these research-based insights, much AL practice within international and South African tertiary education institutions remains located more within the EAP, and sometimes even within an ESL, approach (Henderson \& Hirst, 2007). The reasons for this are often embedded within the intricacies of academic institutional organisation and internal political relations. Jacobs identifies the separation of the 'lifeworlds of Academic Language Practitioners (the world of language and education) and discipline-based specialists', the division of the academy into autonomous disciplinary units, and the assumption that academic disciplines constitute the core curriculum, while AL work comprises a less central service function, as partial explanations for this situation (2005:476). The focus of this paper is on exploring the nature and impact of such contextual dynamics within the particular frame of an effort at humanities cross-departmental collaboration in designing and launching an EAP course for first-year Commerce students. It further locates such institutional and disciplinary issues within the broader context of international and national forces operating upon the university. 


\section{BROADER SOUTH AFRICAN AND INSTITUTIONAL FACTORS IMPACTING UPON THE ESL/AL DEBATE AT THE UNIVERSITY OF NATAL}

Since 1994, South African universities have been complexly affected by both international and national developments. At the national level, the political transformation of our society and the move out of an extended period of international isolation have produced extensive and profound changes for universities. These range from issues of widening access to all South Africans and promoting redress, to deep institutional and curricular restructuring (Moore, 2003; Ensor, 2004). These localised impetuses for change have been contiguous with far reaching international shifts in the higher education sector, arising from the effects of globalisation; the intensification of the technology driven 'information-society'; and changed expectations from society and students. Globally, universities are experiencing a sharper societal focus on their end-user relevance; rising pressures to become more utilitarian; and more pronounced demands for applicability and public accountability (Abbas \& McLean, 2002; Abbot, 2002; Martin \& Etzkowitz, 2000; Sporn, 1996).

As the South African government treads a tricky path balancing needs for economic and social redress amidst the imperatives of globalised commercial competition, international investor skittishness and controlled government spending (Moore, Paxton, Scott \& Thesen, 1998:10), the processes of adjustment in higher education remain challenging (Cloete, Fehnel, Perold, Maassen, Moja \& Gibbon, 2002:127-180; Hesketh, 2005). The ripple effects on higher education of factors such as increased public accountability and diminishing government funding have been felt internationally. In South Africa, however, such effects have been especially acute due to the country's rapid re-entry into a globalised world after the extended isolation of the apartheid years (Angelil-Carter, 1998). Between 1994 and 1997, government policy promoted considerable university growth in student numbers. While overall government funding levels remained stable for the UN, increased enrolments of black students begun during the 1980s had rapidly accelerated in the post-1994 years. This situation presented the university with complex challenges in promoting effective learning for a widely diverse student body and necessitated the provision of intensive academic development programmes, generating pressures over the internal distribution of national funding. How best to promote the academic development of a rapidly changing student body had been, and remains, a contested issue, nationally and within the UN.

Throughout the 1980s, historically white universities grappled with the educational implications of serving new constituencies of black, working class students (Khanyile, 1986). Early educational responses produced 'Academic Support Programmes' focussed on 'fixing [black] students' to fit the dominant ethos of the universities (Bulman, 1996:18-19; Thesen, 1997:489). Such programmes assumed a deficit view of African students and worked with the goal of 'bridging the gap' between the pernicious schooling system of Bantu Education and the existing demands of the university. During this period at the UN, the EAP needs of (the mostly white) UN students were met by two service units, one focusing primarily on students' academic writing needs, the other offering extra-curricular support, mainly for academic reading. Early support for black students comprised add-on tutorials, creating further time burdens for already struggling students. Thus a first-year, credit-bearing EAP Humanities course was offered from 1985 to all black Humanities students. Initially staffed by four service units and one academic discipline, it was later taught solely by staff expert in educational linguistics and housed within a newly established academic department (Department A). 
By the 1990s, historically white, English universities had shifted to a stance of 'Academic Development' that assumed university under-preparedness to meet black students' needs (Pavlich \& Orkin, 1993:3-12). These programmes highlighted academic staff development, along with curriculum renewal and changed teaching-learning processes. Academic Support Programme staff lobbied for these shifts and the central placement of academic development activities within the fabric of academic departments (Bulman, 1996:61). Within the Humanities Faculty at UN, this took the form of an 'integrated' academic development programme, with discipline academics trained in educational development theory promoting curriculum change. Additionally, the newly established Department A housing the EAP course had also launched undergraduate and post-graduate courses in applied and educational linguistics. These arose from a commitment to develop graduates who could impact positively on language and literacy education in the secondary school system from whom the university was admitting its students.

However, the role of academic development processes has often remained marginal to the 'core' activities of academic departments and individual academics (Knapper, 2000:2-4; Kasanga, 1998:6,7), with the complex nexus between language proficiency and successful academic achievement often poorly understood by mainstream academic staff (Webb, 2002: 51; Wood, 2002:164-5). While much innovative curriculum development happened, it was often very dependent on external funding, and the energy of junior staff with limited power. Within the UN, some key aspects of the integrated academic development programme slowly withered as external funding dwindled and significant academic development expertise was systemically lost. Bulman (1996), in surveying academic development programmes in KwaZulu-Natal, found that 'many respondents reported resistance to their efforts to get any kind of "ownership" of the extra tutorial programmes from many academic departments, let alone integration of these into the mainstream tutorials.' However, Clarence-Fincham (1998:12) later argued that 'increasingly...the importance of integrating academic development into mainstream courses, of bringing development initiatives into the core rather than relegating them comfortably to the periphery, has been recognised'. These views suggest differential maintenance of academic development gains within our institutions within complex dynamics often affected by fluctuations in the overall resources available within institutions, faculties, schools and disciplines.

\section{LOCAL INSTITUTIONAL FACTORS IMPACTING ON COURSE DEVELOPMENT}

The WC course emerged at the end of an extended period of gradually intensifying change within the university, precipitated by political and economic factors. By the late 1990s, the UN had responded to the dramatic national changes unfolding for higher education with substantial internal reorganisation, to promote fiscal efficiency and proactive curriculum development. Academics were urged to 'make new marriages'; seeking new partners for financial viability and creative inter-disciplinary synergies. These developments can be linked to the gradually rising global pressures on universities world-wide. The local reorganisation of entire faculties, and the creation of new alignments of disciplines in schools, can be connected to international trends in devolving organisation and management to faculties and schools. Such shifts raise mid-level management authority and accountability (such as holding Heads of Schools far more directly responsible for the financial viability of their schools) and may reduce the autonomy of individual academics (Coaldrake \& Stedman, 1999). Moves 
away from individual academic autonomy are usually strongly resisted, making the task of linking the work of individual academics to organisational goals tricky to navigate.

On the Pietermaritzburg campus, the former Faculties of Humanities and Commerce merged. New academic relationships formed at Faculty Board meetings. Previously strongly insulated departments had to form Schools with weakened disciplinary boundaries. This had complex effects, some creatively generative, others intensifying fears and producing defensive responses protective of the status quo. One product of this process was a new school focusing on language and cultural studies (SLC), comprising, amongst others, modern languages, including Department B (which focused primarily on literary studies) and Department A.

Within this flurry of flux and innovation, the School of Management Studies (SoMS) informed Department B in July 2000 that its new curriculum required all first-year Commerce students to take a compulsory one-semester, 13-week course in academic writing and requested that the SLC design and teach it. Senior SLC management saw this request as stemming directly from new relationships forged between Humanities and Commerce academics within the merged faculty structure. As the SLC faced significantly declining Humanities student enrolments, SLC management readily agreed to the SoMS request, despite such a course falling outside of its established core constituencies and focus. This acceptance of offering a more 'vocationally' oriented course outside of the SLC's usual humanities focus can be linked to international and national pressures on the humanities to retool in the direction of more 'marketable' courses.

To some degree, the SoMS decision can be seen as shaped by market pressures from professional boards demanding greater literacy levels from UN Commerce graduates, and both the EAP and AL orientations in the field of academic development. Assigning full credit to a writing course signalled acknowledgement by the SoMS that most students needed development of their writing abilities. A compulsory course for all students avoided the stigmatisation that English Additional Language (EAL) students sometimes feel when forced to complete separate EAP courses (Thesen, 1997:490). (In 2000 the demographic profile of first-year Commerce students was: African -96 , Indian -93 , White -83 , 'Coloured' -9 . Thus, while African EAL students constituted the largest single group, the majority of students were English Mother Tongue [EMT] speakers). The request for a course specifically tailored to the needs of Commerce students also represented a shift away from much earlier approaches when such students would simply have been encouraged to take existing English literature courses, on the assumption that these were generally beneficially enliterating.

Yet the SoMS decision can also be seen as part of the UN's drift away from a high point of strongly integrated academic development in the Humanities in the early 1990s, as it placed responsibility for the academic literacy development of Commerce students fully in the hands of SLC staff (with little expert knowledge of Commerce discourses), relieving Commerce staff of direct responsibility for explicitly inducting students into these discourses themselves. A further perspective was provided by a senior SLC academic who suggested the SoMS decision was influenced by the wider UN funding crises. That is, given significant SoMS understaffing, a compulsory course offered by another school meant one less course for them to staff and teach.

Responses to the request by school members generally, and by members of Department A and Department B, differed, generating some tensions within the school over how to proceed with negotiating the course structure with the SoMS. To understand why, it is important to 
consider how Department A and Department B staff orientated to the proposed course from different disciplinary domains of intellectual capital, in which they were both strongly invested. A useful starting point is Stein's conception of disciplines as concepts and methods deployed to engage with particular types of questions or phenomena. Over time, these accumulate credibility among experts as establishing standards for judging the validity of the answers generated (2007:93). That is, disciplines are 'methodological lenses' used by communities of practice to seek systematic answers to particular questions. One needs specific expertise to gain entry to disciplinary 'clubs', and because they are social groupings, issues of power are inevitably invoked. Disciplinary communities often feature insularity and territorial spats for power. Disciplines can thus also be seen as 'powerful but constraining ways of knowing' (Lattuca, 2001:2). The variation in responses to the SoMS request sprang from differences in disciplinary 'membership'. The playing out of disputes and tensions over how the course should be conceived and 'pitched' to the SoMS relates to questions of hierarchy and power between disciplines.

Department A staff responded from a sense of praxis expertise rooted in educational linguistic theory, which, as outlined earlier, had increasingly developed a strongly social constructionist understanding of language and literacy development. A key element of this expertise derived from integrating insights from language learning research along with social theories of learning. Such insights led to their understanding that decontextualised grammar instruction often has little impact upon students' discursive and argumentative writing abilities. Consequently, the EAP course offered by Department A had shifted away from focusing on discrete language skill development. That course was underpinned by views of academic reading and writing as socially constituted meaning-making processes, shaped by specific norms and values. This meant supporting students in identifying and understanding academic writing as an expression of academic subcultures into which students had to navigate their entry. Department B's staff expertise lay in literary and cultural studies. Nevertheless, they tended to see themselves as the natural guardians of good language and writing practice, the foundations of which, for them, lay in the promotion of grammatical mastery. Partially, the evolution of Department A from service units to academic discipline, with ongoing responsibility for service writing courses, meant the internal departmental divide between literary and writing instruction frequently found in America (Bullock \& Trimbur, 1991), was here manifested across two distinct departments.

In the early 1980s, all Department B courses were literary and presumed English Mother Tongue (EMT) proficiency in analysing mostly canonical literary texts. By the mid-1990s, many black students, minimally prepared in literary interpretation, enrolled in these courses. The resultant crisis (Wood, 2002) led Department B to develop a suite of first-year courses in writing for literary analysis, at differing levels for EMT and EAL students. EAL courses initially focused on grammar, punctuation and paragraph writing and later on argument and essay writing, using a limited number of literary texts. Thus, within the SLC, both Department A and Department B offered EAP courses, with some overlapping focus, but differing underpinning theoretical and methodological approaches. Department A staff drew from communicative, process and critical language teaching paradigms (Savignon, 1983; Zamel, 1987; Raimes, 1991; Fairclough, 1992; Kutz, Groden \& Zamel, 1993), along with academic literacy, genre and systemic functional grammar approaches to the teaching of writing (Lea \& Stierer, 2000; Martin, 1985; Swales, 1990; Hasan, 1996). Department A staff had also been strongly shaped by advocacy work since the early 1980s on the need for changed institutional practices impelled by close engagement with black students' struggles with university culture 
(Bradbury, Damerell, Jackson \& Searle. 1990; Bulman \& Inglis, 1986; Hart, 1990; Hart, 1995; Hart \& Jackson, 1995). Department B staff were influenced by the American rhetorical model of writing development (Buscemi et al., 1998), along with traditional grammar teaching. The departments had never discussed curriculum and materials development processes, or teaching experiences, with each other (Bulman, 1996:112), given the entrenched culture of departmental autonomy and lecturer privacy (Knapper, 2000:2). However, the broader changes in the organisational structures of the university, specifically the regroupings of fairly autonomous 'departments' into schools with clusters of weakly insulated 'disciplines', triggered new forms of relating. Key to this were institutional goals of greater inter-disciplinary collaboration. However, establishing deep, shared understandings of interdisciplinarity within academia is tricky.

Achieving true inter-disciplinarity is an exceptionally difficult task. It can be seen as transferring the methodological lens from one discipline to another; of also aiming for a unifying axiom for a set of related disciplines synthesised at a higher hierarchical level and thereby producing a common goal (Volckmann, 2007:77; Stein, 2007:97). At an individual level, this requires becoming truly expert in two disciplinary domains. At a collective, collaborative level it remains dauntingly demanding on participants, personally and professionally. Stein asserts that 'to spawn healthy endeavours involving more than one discipline the default epistemic position should be one of open-minded disciplinary tolerance, not one of sceptical disciplinary xenophobia' (2007:104-5). Collaboration generated within conditions of chronic fears of reduced resources and disciplinary demise is less likely to produce open-minded tolerance. Even if there is willingness, in principle, to engage from such a stance, such tolerance implies readiness for one's paradigmatic assumptions to be disrupted, perhaps even shattered. In stressful conditions such as those prevailing at UN not many academics open their arms widely and willingly to the energy expenditure likely to follow.

Within the SLC, the senior leadership saw a need for new disciplinary formations within the school, partly as strategic manoeuvring to protect small disciplines from threats of closure, and partly as intellectually appropriate responses to global changes in society and higher education. However, while inter-disciplinarity was invoked as a generally desirable good, by university management as well as middle management, it was not analysed, explored or explained. This was not a condition unique to UN - Moran describes inter-disciplinarity as 'the most seriously under thought ... concept in the modern academy' (cited in Abbas \& McLean, 2002:8). In the context of the WC course design process, the contributing members thus moved relatively warily into the process without a clear analytical awareness of the full scope of innovatory disciplinary possibilities it presented. Yet, intuitively, all were aware of potential losses - both by participating in innovation, and by resisting it.

The collaboration between Departments A and B can thus more accurately be identified as a limited cross-disciplinary endeavour by which the axioms of one discipline were placed upon those of the other discipline, leading to connections and an orientation towards a specific disciplinary perspective (Stein, 2007). That is, offerings were made from each disciplinary perspective, and largely juxtaposed against each other, without profound engagement with, and reconfiguring of, the other disciplinary paradigm. 


\section{THEORETICAL CONTEXT FOR UNDERSTANDING THE CURRICULUM DESIGN PROCESS}

Ideally, EAP course design needs to be a systematic, planned set of processes providing a coherent means of generating a course that satisfies the key stakeholders. Key elements of the process include needs analysis, establishing course goals and objectives, conceptualising pedagogic approach and content, selecting and developing materials and activities, consideration of resources and constraints, and evaluation of the course (Dubin \& Olshtain, 1986; Graves, 1996; Jordan, 1997; Flowerdew \& Peacock, 2001). Reports of course development processes often focus on issues of needs analysis and resources and constraints in pedagogically localised ways (e.g. Edwards, 2000), rather than overtly locating these processes within more complex institutional dynamics. However, as Benesch points out:

every academic situation presents a different set of hierarchical and sometimes contradictory needs, including governmental, institutional, departmental and classroom ones, complicating the development of English for Academic Purposes curricula. Decisions about how much change can be effected in the target situation depend on local conditions, including the EAP teachers' status, the receptivity of content teachers, the political climate in the academic institution and country. (1996:726)

The course design process for WC was subject to competing tensions stemming from the institutional factors previously outlined, producing push-pull forces of perceived benefit and threat from collaboration.

Despite this, a pragmatic, eclectic approach prevailed, drawing most strongly on Department A staff experience in developing writing courses from within communicative, process and genre paradigms. There was general commonality, in the focus on macro discourses of classroom genres, with aspects of the rhetorically influenced experience from Department B. Careful reflection on how the particularities of such forces shaped the design of WC may help us better navigate future complexities invoked in the design of related courses.

In the next section of the paper I describe the process of course design for EWC, linking aspects of this process to the broader factors already outlined.

\section{CURRICULUM DESIGN PROCESS}

The early design process was driven more by the intricacies of cross-disciplinary negotiation between Departments B and A, than by detailed articulation of stakeholder needs from the SoMS. While the immediate School environment overtly encouraged collaborative, interdisciplinary ventures, deeper, ultimately more entrenched institutional hierarchies ran counter to these. Given the extended time taken up with the negotiating processes, we were unable to seek out perceptions from existing students.

In early August 2000, SLC staff were informed of the proposed course, which the SLC management saw as a creative, strategic opportunity to nurture a more inter-disciplinary school ethos; as well as financially vital. Staff members were encouraged to buy into this vision. Consequently the course was flagged as the first 'school-based', as opposed to 
'discipline-based' course, and staff in vulnerable disciplines were encouraged to teach in it. Yet, at initial formal and informal gatherings, differing procedural strategic emphases emerged.

Within consensus over stakeholder consultation with SoMS staff, Department A members argued the need to establish clear boundaries over feasible outcomes for the course. This came from extended previous experiences with discipline-based staff beliefs that Department A could "grammatically fix" students in a few weeks. However, Department B staff felt we should avoid any mention of limits, fearing that the SoMs would take the course elsewhere. Department A staff felt that their experiential basis for their view was discounted:

'... [X (a senior school academic)] came and asked me not to get too angry ... they were trying to shut me up.... I just couldn't academically do that - ...you can't pull the wool over people's eyes, you've got to make them aware of what this course can or can't do.' (2005, Department A staff member).

In addition, considerable informal debate occurred over the place of grammar teaching. While Department A staff argued for integrated grammatical instruction, founded upon genre and Systemic-Functional Grammar insights, a senior member of Department B argued that students needed instruction in traditional grammar in order to improve the linguistic accuracy of their writing. Additionally, he argued that introducing students to Systemic Functional Grammar would simply confuse the students with complex metalanguage. He then commented that perhaps a colleague from a sister campus (responsible for language work but without formal educational linguistic qualifications) would be best equipped to manage such a strategically sensitive venture. Department A staff experienced such views as inherently dismissive of their disciplinary expertise and experience.

Underlying these debates were unarticulated, but real disciplinary contestations concerning territory, control and pedagogic ideology. Becher argues that 'one of the striking features of academic life is that nearly everything is graded in more or less subtle ways ... there is also a prestige which attaches to some subjects in particular and in some areas even a rough pecking order between the component specialisms' (1989:56). At issue in the SLC context were fault lines over who ultimately had the right to define 'effective' English language teaching (Blair, 1988; Smith, 1988). These emerged due to the pervasive disciplinary vulnerability amidst the broader financial and structural institutional pressures. In less pressured preceding years, the relative hierarchical relations between disciplines (Schuster, 1991:89) lay dormant, while different types of writing courses co-existed. There had been no imperatives for staff to engage their ideological differences over the nature and ownership of the academic literacy development of students.

Such tensions are similar to those in other parts of the globe (Blair, 1988; Mahala, 1991) where the location and forms of language development intervention have been intensely debated. Mahala (1991:773) argued (in relation to Writing Across the Curriculum [WAC] developments) that deep questions about the educational processes propelling, and the institutional structures controlling, undergraduate curricula, that should emerge when the language development needs of students within disciplinary contexts are raised, are often softened. This happens so as not to destabilise the institutional structures containing conflicting professional and ideological interests within the university. While WC is not a WAC course, the question of how to meet the particular needs of Commerce students within a context of major institutional flux and disciplinary vulnerability, amplified emotional 
overtones to assumptive and strategic differences over needs analysis and core course design principles. It also tapped into slippery power relations between Department B (a longestablished, high status Humanities discipline) and Department A (a young, far less firmlyentrenched discipline).

Early in August 2000, SLC management asked members of Departments A and B to commit to the course. One member of Department B, two permanent members of Department A, and two contract staff from Department A, did so. The Department B staff member reports imploring other members of her department to participate, to no avail. This is suggestive of debates within Department B over their role in relation to service writing courses. Thus, as a cross-disciplinary collaboration, the venture began with a serious imbalance of contribution from the two disciplines. Two meetings with SoMS staff were held in later August. These clarified a focus on equipping students to write well for their studies. It was not to be a business communication course. The only specific request from the SoMS staff was to get students to 'read for current affairs' relevant to their studies. As an SLC management member noted, beyond this 'they didn't seem particularly interested in details of content: "Oh well, you know best what to do - you go ahead and do it".'

As the design team was starting work in late September 2000, a senior Department B member proposed their staff member as course co-ordinator at the SLC Board. Partly, this was pragmatically strategic, as her spouse held a significant position in the SoMS. However, Department A staff also perceived this as an attempt by Department B to keep control:

'...I think that was what Department B wanted, quite frankly, they wanted control...'

(Department A staff member, 2005).

This was obliquely confirmed in an interview with a senior manager of the SLC, who commented on the Faculty handbook coding and naming of the course, which was clearly linked to Department B. That is, although flagged as a 'School' course, Department B built in administrative ownership, possibly as an opening to full claim of the course in the event of continuing decline in their core course enrolments.

With teaching starting in February 2001, the team members were acutely conscious of the pressured time frame. Given the time pressures and with no dedicated institutional resources for comprehensive needs analysis, it was not possible to research the specific demands of first-year Commerce writing tasks, how these shift throughout the degree and how these link to professional writing demands. Despite these constraints, it was evident that, given SoMS understaffing and their large first-year class numbers, first-year students produce little extended writing. This situation gradually changes as they proceed to senior years.

Initially, the team discussed two issues. First we explored to what extent we could assume the existence of a teachable, transferable generic core of academic writing skills (Breier, 1998:73; Thesen, 1997:491) versus diverse, contextually specific academic literacies (Hyland \& HampLyons, 2002; Clark \& Ivanic, 1997; Reynolds \& de Klerk, 1998; Swales, 1990; Street, 1995; Taylor, Ballard, Beasley, Bock, Clanchy \& Nightingale, 1988). Secondly, we debated how much of a process and meta-cognitive approach was necessary and possible. Given pressures to deliver quickly and effectively, and to preserve the embryonic cross-disciplinary collaboration, much debate was pragmatically shelved rather than taken to a point of genuinely consensual resolution. We accommodated as many preferences as possible, thereby contributing to a rather crowded, initially slightly disjointed course. Though aware of ideal 
course design process (Hibbert, 1999:37), the urgency required us to get on with materials development:

...we took it [needs analysis] very seriously - ... as expressed by the Commerce people. And we certainly tried to satisfy their needs as far as possible.... We bore in mind the kind of difficulties that Commerce students might have in being expected to do a course that they had not opted for, ... we also looked at our strengths as teaching staff ... I don't think there would have been time [to consult students] ... we were approached close to exam time. (Course Co-ordinator, 2005)

With only 13 weeks' contact, we decided on a task-based rather than content-based course. The question of generic versus discipline-specific writing demands took longer to resolve. One Department A member argued strongly for in-depth needs analysis of the range and form of Commerce student writing genres. The Department B member felt we could work from generic rhetorical structures, such as explanation and description, to teach logical, persuasive writing. The team reached a pragmatic compromise. We agreed that the Department A member could gather a limited collection of samples of student writing and textbooks in Economics and use these along with material from Woodward-Kron (1997), to develop materials for the teaching of essay writing.

A Department A member then drafted possible course outcomes (see Appendix B). These fell into the following categories identified by Stern:

a) Proficiency goals, focussing here upon students' general academic writing and reading competencies;

b) Cognitive goals, with linguistic and cultural knowledge of the 'sub-cultures' of academia being developed in students;

c) Affective goals, in terms of aiming to develop more positive attitudes in students, towards reading, in particular, and the need for planned, strategic approaches to academic writing tasks; and, finally,

d) Transfer goals, towards which we were aiming to build student's capacity to learn and apply their learning, through the portfolio and reflection papers (1992, cited in Graves, 1996:17).

The other team members accepted these and we then took them to SoMS staff, who also readily accepted them; perhaps another expression of their 'you are the experts, you don't need to worry us' attitude.

Pragmatic, time-driven course development meant we drew extensively on prior teaching and materials development. People volunteered to develop materials where they felt confident of their expertise. Additionally, we imported and adapted relevant material from existing courses (Graves, 1996:26):

...I couldn't believe people's good will, because we broke up the work into chunks, we each had a certain number of periods that we were allocated, and we asked that people would design material that the students would use and then a kind of teacher's guide, so that we would all know exactly where we were.... There was a very positive attitude. (Course Co-ordinator, 2005) 


\section{COURSE STRUCTURE AND MATERIALS DESIGN}

We organised the course structure and content around a number of intersecting principles (Graves, 1996:29; Flowerdew, 2005):

1) A gradual shift from the experiential to the abstract; ${ }^{2}$

2) Task-based (Graves, 1996:22), using a range of writing tasks to introduce students to a variety of academic classroom genres (Johns, 1995:282), and including a focus on the fact of disciplinary variation of written genres across subjects; ${ }^{3}$

3) A strong competency focus; ${ }^{4}$

4) Development of genre awareness (Swales, 1991; Taylor et al., 1988; Johns, 1995:281$2) ;^{5}$

5) Writing as a spiralling, recursive process in which formative assessment is crucial (Zamel, 1987; Johns, 1995:278-280); ${ }^{6}$

6) Relevance of topic selection: either to students' immediate situation, or current business affairs ${ }^{7}$

7) Promotion of meta-cognitive reflection throughout the course (Moon, 1999; Sutherland, 1996) ${ }^{8}$

8) An 'open book' summative assessment by means of a three-hour, single essay exam enabling students to prepare readings meaningfully in advance and focus on building a sound argument in the examination; ${ }^{9}$

9) Use of a mixture of commercially published and self-generated materials. ${ }^{10}$

By the end of the very limited time available for the design, we had a complete course to launch. It was a generic, stand-alone EAP course, with popular topics relating to the world of business serving as the content vehicle for general academic literacy competency development. From Department A it received a strong focus on the writing process, filtered through a genre lens, along with a foregrounding of integrated grammatical competencies development. Department B contributed the focus on generic essay 'types' of argument, foragainst, etc., and the need to develop students' critical research, reading and writing abilities through a 'long' research essay. Thus, while the course design process was clearly limited and problematic in some key respects, it was robust enough to launch the course, which has subsequently evolved into a stronger, more streamlined, coherently articulated and relevant form.

\section{CONCLUSION}

While the broader context of acute national and institutional change produced complex relational dynamics between the contributing disciplines, the process of course design survived these. Partially this can be attributed to the vision of SLC management at the time, in consciously promoting a school identity, and deploying a consultative, low-key management style. It can also be attributed to the commitment of the members of the course design team, who shared a strategic and pragmatic sense of the need for the course for the School, and the students, and thus the imperative for an effective design process. The team members foregrounded these aspects, worked constructively with their pedagogical differences, and felt personally benefited by the collaboration.

However, as an enterprise (among several promoted by the SLC management) to build a strong, inter-disciplinary school identity, the project was fragile, and has withered. Perhaps 
this stemmed from the reality that conditions for growing true inter-disciplinarity were never present, with the collaboration remaining at the level of pragmatic cross-disciplinary working alongside each other. The roots of this fragility were evident in the imbalance in the course design team, with five from Department A and only one from Department B. The Department B staff member commented: '... it's obvious that it was lacking in balance, and it was a bit of a difficult situation, being co-ordinator, and yet not being the kind of person who was responsible for driving that process...' That is, the time constraints, and the pressure of the members' other commitments to their disciplines, constrained the building of genuinely shared frameworks of academic literacy development within the Commerce field, underpinned by common, robust engagement with theory and research in this field. Perhaps to achieve this, we would have needed a joint commitment to researching the discourses of Commerce subjects and, probably, also commitment from Commerce faculty staff to some contribution to such a research project.

Although Department B leadership saw WC as a strategic buffer course for the department, as much as for the school, this view did root widely amongst the staff. While the Department B member articulated personal benefits from participating in the course: '... I found the group immensely supportive, [and] was really inspired... by the way that Department A people were accustomed to working together', pressures to complete a $\mathrm{PhD}$ (a literary study) took her permanently out of the course. Ultimately, promoting true, ongoing inter-disciplinarity in relation to such EAP course development also depends on all contributors identifying ongoing professional benefits from sustained participation within them. This we did not achieve as a team within this project.

Further institutional forces stemming from national policies for rationalising higher education in South Africa have amplified localised, existing factors undermining such ventures with inter-disciplinary aspirations:

...structures and cultures of a number of South African universities inhibited [inter-disciplinary] development, restricting enthusiasts' capacity to effect envisaged changes and to sustain curriculum innovation (Hesketh, 2003). Pioneer curriculum developers initiated hasty, collaborative, transdisciplinary reform processes, which relied on participants' strong commitment to the joint endeavour but there has been little support for programmatic organisation where processes, discourses and resources cut across disciplines. The pockets of effective innovation that have emerged in this manner have been achieved at high personal cost to academics with enormous workloads and pressures and have often been experienced as unsustainable. (Hesketh, 2005)

While, as the former course co-ordinator commented, 'there's a stigma attached to first year teaching, especially service courses' amongst many staff, mounting institutional pressures on staff have exacerbated reluctance to commit to sustained participation in demanding academic development initiatives. In the wake of two merger processes, the initial 'window' opened in the SLC for such ventures by the organisational restructuring in the late 1990s has closed as the constituent disciplines have been unbundled and absorbed into three cross-campus schools, spread across $80 \mathrm{~km}$. Department A and Department B are now in different schools. Financial fallout from the mergers (e.g. moratoriums on replacing staff) have increased pressures, and perceptions of vulnerability, for everyone. Department B subsequently decided that it has to concentrate on its 'core business' (literary and cultural studies) and, given an 
acute financial crisis regarding contract staff early in 2005, has had to abandon its own suite of small-group, writing courses. A former SLC management member's comment on Department B's withdrawal from writing courses is: '...there were larger forces that prohibited this [collaborative venture] from working.... And the phrase 'core business' seems to be an attempt to put a positive spin on ... what is a reduction in resources - 'Why do you need to concentrate on your core business? Because in fact you don't have resources to do these other things!'.... There's no such thing as a pre-given core business - it just means you have to choose.'

WC is still offered and has evolved into a more coherent form with stronger inclusion of Commerce-specific genres such as business reports. But it is now solely the responsibility of Department A, which faces a precarious future. Department A's current school is presently debating the possibility of giving up responsibility for the course to concentrate its dwindling staff resources on the academic literacy needs of Humanities students. The genesis of WC represents an intriguing 'moment' suggestive of unrealised, yet rich possibilities for productive, collaborative course design across disciplines. The course was born out of an opening space between disciplinary boundaries arising from the nexus of global and local factors. The ongoing tightening of resources available to both contributing disciplines, linked at least partially to the continuing effects of these same forces, has led to a shutting down of that space.

Finally, from the perspective of New Literacy Studies research insights, the very existence of the WC course can be strongly questioned and critiqued as a sub-optimal intervention to enhance the written communicative capacities of the Commerce students. Interventions thoroughly consistent with an Academic Literacies orientation would promote a very different form of inter-disciplinary collaboration, with the intervention mainstreamed and integrated into commerce subjects such as Management Studies and Economics. One such model is that articulated by Jacobs (2005, 2007) where academic literacy practitioners work deeply collaboratively, over extended periods of time, with discipline experts in order to render tacit norms and values of the discourses of the discipline visible to the discipline experts who can then communicate them to their students. Such a model is very likely to disrupt the existing social organisation of the university, as alluded to by Mahala (1991), and so presupposes high commitment on the part of both academic literacy practitioners and the institution to work beyond established comfort zones. It also implies the need for academic literacy practitioners to be members of their own disciplinary 'tribe' and, specifically, a higher education disciplinary community of practice (Bath \& Smith, 2004), within an organisational structure with sufficient institutional credibility. From this perspective, perhaps, a number of the difficulties in the WC collaborative venture could be seen as stemming from neither contributing department owning 'Higher Education Studies' as its core disciplinary orientation. While Department A had long-standing praxis links with regional Higher Education practitioners, its other commitments to its humanities undergraduate major and post-graduate courses perhaps diluted its members' capacity to develop and commit to a strongly research-backed argument for an integrated mainstream intervention that might have persuaded the SoMS of the worth of increasing their already heavy workload.

Sustainable collaborative EAP course design and intervention between distinct academic units thus hinges on a very finely tuned balance between changes to, and maintenance of, the academic status quo; strong alignment between the goals of the venture and contributing 
disciplines' core orientations; sufficiency of institutional resources and incentives; and evenly distributed commitment to such curricular innovation.

\section{Acknowledgements}

Sue Mathieson, Dr Billy Meyer and two anonymous reviewers for helpful comments and editorial suggestions. Any remaining faults are entirely my own responsibility.ENDNOTES

\footnotetext{
${ }^{1}$ A senior member of the former SLC management, one Department A and the Department B member of the design team were interviewed, with their informed consent. Of the other design team members, one has emigrated and the other has died. I tape-recorded and transcribed the three interviews, and analysed them qualitatively. (See Appendix A for interview questions.)
}

${ }^{2}$ Tasks shifted from narrowly focused, and/or more experiential, to increasingly complex, academically abstract. Initial formal writing tasks were paragraph length, with a narrow topic requiring learners to draw on information from only one reading. The complexity of demands was gradually increased, with students progressing to two-paragraph assignments, a 600-word explanation essay, with few readings, and finally a 1200-1500-word multi-sourced research essay. (See Appendix C for an example task.)

${ }^{3}$ Given the shortness of the course, we could only focus on relatively generic 'cognitive genres' (Bruce, 2005: 242) rather than explore discipline-specific genres in different Commerce subjects.

${ }^{4}$ This meant introducing students to issues such as selecting reading strategies according to a specific purpose, careful topic analysis, selective note-making techniques and ways of organising paragraphs. Shortly before their research essay we planned detailed library orientation.

${ }^{5}$ We foregrounded writing as socially constructed subcultures, with students having to uncover norms for particular social purposes, leading to different discursive and grammatical constructions. So we planned discussions about why informal styles of writing were acceptable in students' reading journals but not in their essays; why both the research essay and portfolio reflection paper were evidence-based arguments, but with different structures and styles. We incorporated Woodward-Kron (1997) to highlight the macro-discourse structures of the argumentative essay and later, micro-structures typical of academic discourse, such as nominalisation.

${ }^{6}$ This entailed introducing students to our assessment criteria through structured peer editing. It also meant providing extensive opportunities to plan, draft and rewrite both major term essays, using detailed formative feedback.

${ }^{7}$ These included:

- the concept of negotiation of meaning within the transactional model of communication and applying this model to aspects of their academic life;

- inter-cultural communication in the workplace;

- $\quad$ evaluating affirmative action policies and practices in South African business;

- food and economic implications, for their major research essay, where students formulated a narrow research focus and sourced their own readings (the scope and required structure for the research essay were strongly shaped by features of some of Department B's writing courses);

- $\quad$ problems faced by women in the business world.

${ }^{8}$ For example, by assigning:

- $\quad$ a double-entry reading journal in which students wrote précis and personal responses (this task was also a direct response to the request by the SoMS to promote engagement with current affairs and increase students' motivation to read);

- Submission of a final portfolio of selected course work, some samples of discipline-based writing and a final reflection paper tracing the nature and shifts in their attitudes to, and experiences of, reading and writing. 


\footnotetext{
9 This followed the same format as the timed test, with scaffolded support for students through provision of written guidelines for working with the readings, along with reading questions and in-class time for peer group discussion of the readings. This last was insisted upon by the Department B staff member, who felt it was vital to see what students could do unaided by staff. Department A staff members reluctantly acceded to this, despite their preferred view, being that it was our last opportunity in too short a course to support and teach weak students in how to unpack the arguments of complex readings.

${ }^{10}$ In addition to Woodward-Kron (1997), we also prescribed a South African textbook (Cleary et al., 1999), despite unease about its simplistic treatment of issues. Given the basic content, we supplemented with other readings. Commitment to use of current business affairs issues as assignment topics necessitated sourcing readings from recent newspaper and magazine articles.
}

\section{REFERENCES}

ABBAS, A \& M McLEAN. 2002. Towards a sociology of teaching and learning: politicising pedagogic praxis [Online] Seminar presented at: Towards A Sociology of Higher Education, 22 November 2002, University of Bristol. Available: http://bristol.ac.uk/education/research/esrc seminar/papers/1 MMAAinterdis1.pdf [2009, 12 January].ABBOT, A. 2002. The Disciplines and the Future. In Brunt, S (Ed), The Future of the City of Intellect: The Changing American University. Stanford: Stanford University Press.

ANGELIL-CARTER, S. (Ed). 1998. Access to Success: Academic literacy in higher education. Cape Town: University of Cape Town Press.

BATH, D \& C SMITH. 2004. Academic Developers: An Academic Tribe Claiming Their Territory in Higher Education. International Journal for Academic Development, 9(1):9-27.

BECHER, T. 1989. Academic tribes and territories: Intellectual inquiry and the cultures of disciplines. Milton Keynes, England: Society for Research into Higher Education and the Open University Press.

BENESCH, S. 1996. Needs Analysis And Curriculum Design in English for Academic Purposes: An Example of a Critical Approach. Tesol Quarterly, 30:723-738.

BLAIR, C. 1988. Only One of the Voices: Dialogic Writing across the Curriculum. College English, 50(4):383-389.

BRADBURY, J, C DAMERELL; F JACKSON \& R SEARLE. 1990. ESL Issues Arising From the 'Teach-Test-Teach' Program. Searching For Relevance: Contextual Issues in Applied Linguistics in Southern Africa. South African Applied Linguistics Association: University of Natal, Durban.

BREIER, M. 1998. The role of the generic skill in lifelong learning: panacea or pipe-dream? Journal of Education, 23:73-100. School of Education, University of Natal, Pietermaritzburg.

BRUCE, I. 2005. Syllabus design for general EAP courses: A cognitive approach. Journal of English for Academic Purposes, 4(3):239-256.

BULLOCK, R \& J TRIMBUR. 1991. The Politics of Writing Instruction: Postsecondary. Portsmouth, NH: Boynton Cook.

BULMAN, F. 1996. A regional study of Academic Development and its roots in Academic Support. Unpublished MA thesis: University of Natal, Pietermaritzburg.

BULMAN, F \& M INGLIS. 1986. Looking At Course Design in Learning, Language and Logic. ASPects 7. Pietermaritzburg: University of Natal.

BUSCEMI, S, A NICOLAI \& R STRUGALA. 1998. The Basics: A Rhetoric and Handbook. Boston: Irwin McGraw-Hill. 
CELCE-MURCIA, M. 1991. Grammar Pedagogy in Second and Foreign Language Teaching. TESOL Quarterly, 25(3):459-480.

CLARENCE-FINCHAM, J. 1998. Voices in a University: A Critical Exploration of Black Students' Responses to Institutional Discourse. Unpublished doctoral dissertation: University of Natal, Pietermaritzburg.

CLARK, R \& R IVANIC. 1997. The Politics of Writing. London: Routledge.

CLEARY, S (Ed). 2003. The Communication Handbook. ( $2^{\text {nd }}$ Edition) Lansdowne: Juta.

CLOETE, N, R FEHNEL, H PEROLD, P MAASSEN, T MOJA \& T GIBBON. 2002. Transformation in higher education: global pressures and local realities in South Africa. Lansdowne: Juta.

COALDRAKE, P \& L STEDMAN. 1999. Academic Work in the $21^{\text {st }}$ Century. Changing roles and policies [Online]. Occasional Paper Series. Higher Education Division, Department of Education, Training and Youth Affairs. Commonwealth of Australia. Available: http://www.colorado.edu/geography/gfda/resources/lifelongdevelopment/academicworkin21c.pd f/ [2009. 15 January].

DUBIN, F \& E OLSHTAIN. 1986. Course Design. Cambridge: Cambridge University Press.

EDWARDS, N. 2000. Language for business: effective needs assessment, syllabus design and materials preparation in a practical ESP case study. English for Specific Purposes, 19(3):291296.

ENSOR, P. 2004. Contesting discourses in higher education curriculum restructuring in South Africa. Higher Education 48:339-359.

FAIRCLOUGH, N. (Ed). 1992. Critical Language Awareness. London: Longman.

FLOWERDEW, L. 2005. Integrating traditional and critical approaches to syllabus design: the 'what', the 'how' and the 'why?' Journal of English for Academic Purposes, 4(2):135-147.

FLOWERDEW, L \& M PEACOCK, 2001. The English for Academic Purposes curriculum: Issues, methods and challenges. In Flowerdew, L\& M Peacock (Eds), Research Perspectives on English for Academic Purposes. Cambridge: Cambridge University Press.

GEE, J. 1990. Social linguistics and literacies: Ideologies in discourses. London: Falmer.

GRAVES, K. 1996. A framework of course development processes. In Graves, K (Ed), Teachers as Course Developers. Cambridge: Cambridge University Press.

HALLIDAY, M. 1994. An Introduction to Functional Grammar. ( $2^{\text {nd }}$ Edition). London: Arnold.

HART, M. 1990. University E.A.P. courses and transformation in the South African context: the Learning, Language and Logic course at the University of Natal, Pietermaritzburg. ASPects 7. University of Natal, Pietermaritzburg.

HART, M. 1995. 'The singer not the song': What students have to tell us about writing. Constitutionally Enshrined Multilingualism: Challenges and Responses. Proceedings of the $15^{\text {th }}$ Annual Conference of the Southern African Applied Linguistics Association.

HART, M \& F JACKSON. 1995. Portfolios: Problems and Possibilities. Constitutionally Enshrined Multilingualism: Challenges and Responses. Proceedings of the $15^{\text {th }}$ Annual Conference of the Southern African Applied Linguistics Association.

HASAN, R. 1996. Literacy, everyday talk and society. In Hasan R \& G Williams (Eds), Literacy in society. London: Longman. 
HENDERSON, E. \& R HIRST. 2007. Reframing academic literacy: Re-examining a short course for 'disadvantaged' tertiary students. English Teaching: Practice and Critique, 6(2):25-38.

HESKETH, J. 2005. Universities and change: how principles of democracy and equality can promote quality education. Paper presented at Kenton Education Conference, Mpekweni, South Africa, 27-30 October 2005.

HIBBERT, L. 1999. An outcomes-based assessment framework for courses in English educational development. SAJALS: Southern African Journal of Applied Language Studies, 7(1):27-39.

HYLAND, K \& L HAMP-LYONS. 2002. EAP: Issues and directions. Journal of English for Academic Purposes, 1:1-12.

HYMES, D. 1972. On Communicative Competence. IN PRIDE, JB \& J HOLMES. (Eds) Sociolinguistics. Harmondsworth: Penguin.

JACOBS, C. 2005. On being an insider on the outside: new spaces for integrating academic literacies. Teaching in Higher Education, 10(4):475-487.

JACOBS, C. 2007. Mainstreaming academic literacy teaching: implications for how academic development understands its work in higher education. South African Journal for Higher Education, 21(7):870-881.

JOHNS, A. 1995. Teaching Classroom and Authentic Genres: Initiating Students into Academic Cultures and Discourses. In Belcher, D \& G Braine (Eds), Academic Writing in a Second Language. Norwood, NJ: Ablex Publishing.

JORDAN, R. 1997. English for Academic Purposes: a guide and resource book for teachers. Cambridge: Cambridge University Press.

KASANGA, L. 1998. English for Special/Academic Purposes: Form and Function in South Africa. Paper presented at South African Association of Academic Development Conference 'Capacity Building for Quality Teaching and Learning in Further and Higher Education'. University of the Free State.

KHANYILE, V. 1986. Keynote Address: Academic Support Programmes Conference. ASPects 7. University of Natal, Pietermaritzburg.

KNAPPER, C. 2000. Editorial: The politics of academic development. International Journal for Academic Development. Taylor \& Francis.

KUTZ, E, S GRODEN \& V ZAMEL. 1993. The Discovery of Competence: Teaching and Learning with Diverse Student Writers. Portsmouth: Boynton/Cook Heinemann.

LATTUCA, L. 2001. Creating Interdisciplinarity: Interdisciplinary Research and Teaching among College and University Faculty. Vanderbilt University Press.

LAVE, J \& E WENGER. 1991. Situated learning: Legitimate peripheral participation. New York: Cambridge University Press.

LEA, M. 2005. Communities of practice in higher education. In Barton, D \& K Tusting (Eds), Beyond communities of practice: Language, power and social context. Cambridge: Cambridge University Press.

LEA, M \& B STIERER (Eds). 2000. Student Writing in Higher Education: New Contexts. Buckingham: The Society for Research into Higher Education \& Open University Press.

MAHALA, D. 1991. Writing Utopias: Writing across the Curriculum and the Promise of Reform. College English, 53(7):773-789.

MARTIN, BR \& H ETZKOWITZ. 2000. The origin and evolution of the university species. VEST, $13(3 / 4)$. 
MARTIN, JR. 1985. Factual Writing: Exploring and challenging social reality. Geelong, Victoria: Deakin University Press [republished by Oxford University Press, 1989].

MCKENNA, S. 2004. A critical investigation into discourses that construct Academic Literacy at the Durban University of Technology. Unpublished doctoral dissertation, Rhodes University.

MOON, J. 1999. Learning journals: their uses across the disciplines. Partnerships across the Disciplines. In M. Graal \& R Clark (Eds), Proceedings of the $6^{\text {th }}$ Annual Writing Development in Higher Education Conference.

MOORE, R. 2003. Curriculum Restructuring in South African Higher Education: academic identities and policy implementation. Studies in Higher Education, 28(3):303-319.MOORE, R, M PAXTON, I SCOTT \& L THESEN. 1998. Retrospective: Language development initiatives and their policy contexts. In Angelil-Carter, S (Ed), Access to Success: Academic Literacy in Higher Education. Cape Town: University of Cape Town Press.

PAVLICH, G \& M ORKIN (Eds). 1993. Diversity and Quality: Academic Development at South African Tertiary Institutions. Johannesburg: CASE.

RAIMES, A. 1991. Out of the woods: Emerging traditions in the teaching of writing. TESOL Quarterly, 25:407-430.

REYNOLDS, J \& V DE KLERK. 1998. Entering the Discourses of the University. SAJALS: Southern African Journal of Applied Language Studies, 6(1):43-58.

SCHUSTER, C. 1991. The Politics of Promotion. In BULLOCK, R \& J TRIMBUR. (Eds) The Politics of Writing Instruction: Postsecondary. Portsmouth, NH: Boynton Cook.

SAVIGNON, S. 1983. Communicative Competence: Theory and Classroom Practice. Texts and Contexts in Second Language Learning. Reading, Massachusetts: Addison-Wesley.

SMITH, L. 1988. Why English Departments Should 'House' Writing Across the Curriculum. College English, 50(4):390-395.

SPORN, B. 1996. Managing University Culture: An Analysis of the Relationship between Institutional Culture and Management Approaches. Higher Education, 32(1):41-61.

STEIN, Z. 2007. Modeling the Demands of Interdisciplinarity: Toward a Framework for Evaluating Interdisciplinary Endeavors. Integral Review, 4:91-107 [Online]. Available: http://integralreview.org/documents/Stein,\%20Nicolescu\%20Modelling\%20Demands\%2of \%20Interdisciplinarity\%2004,\%202007.pdf [2009, 12 January].

STREET, B. 1995. Social Literacies: critical approaches to literacy in development, ethnography and education. London: Longman Group.

SUTHERLAND, L. 1996. Meta-cognition, Self-evaluation and Academic Literacy. Language and Literacies: Proceedings of the $16^{\text {th }}$ Annual Conference of the Southern African Applied Linguistics Association.

SWALES, J. 1990. Genre Analysis: English in Research and Academic Settings. Cambridge: Cambridge University Press.

TAYLOR, G; B BALLARD; V BEASLEY; H BOCK; J CLANCHY \& P NIGHTINGALE . 1988. Literacy by Degrees. Milton Keynes: Open University Press.

THESEN, L. 1997. Voices, Discourse, and Transition: In Search of New Categories in EAP. TESOL Quarterly, 31(3):487-511.

VOLCKMANN, R. 2007. Transdisciplinarity: Basarab Nicolescu talks with Russ Volckmann. Integral Review, 4:73-90 [Online]. Available: http://integralreview.org/documents/Volckmann,\%20Nicolescu\%20on\%20Transdisicplinarity\%204,\%202007 .pdf [2009, 12 January]. 
WEBB, V. 2002. English as a Second Language in South Africa's tertiary institutions: a case study at the University of Pretoria. World Englishes, 21(1):49-61.

WENGER, E. 1998. Communities of practice: Learning, meaning and identity. Cambridge: Cambridge University Press.

WOOD, F. 2002. Life Jacket or Lead Weight? English for Special Purposes and the Future of English Departments. In Sarinjeive, D \& R Balfour (Eds), English in Transition: debates, research, possibilities. Howick: Brevitas.

WOODWARD-KRON, R. 1997. Writing in Commerce (Revised Edition). Callaghan, Australia: Centre for the Advancement of Learning and Teaching, The University of Newcastle.ZAMEL, V. 1987. Writing: The Process of Discovering Meaning. In Methodology in TESOL: A Book of Readings. New York: Newbury House.

\section{Appendix A}

\section{Curriculum Development Process Interview Questions}

Curriculum Designer Team Members' Interviews

1. What can you remember of how you learnt of the proposed course?

Time frames for developing the course?

How the design team came into being?

2. What were the most significant factors shaping the way the course was designed?

3. Why did you get involved in the design and implementation of the course?

4. What was the design process?

5. Was any form of needs analysis conducted? If yes, what form? If no, why not?

6. How did we arrive at the outcomes of the course?

7. How did we arrive at the structure and the content of the course?

8. Where did we have most consensus on the structure and content?

9. Where did we have most disagreement on the structure and content?

10. What do you feel was most successful about the Curriculum Design process?

11. What do you feel was least successful about the CD process?

12. What comments do you have about the process as a collaboration between Department A and Department B staff?

13. How did you feel about the involvement of Department B and Department A staff in the process? Did this bring any personal benefits/losses?

Did this bring any disciplinary benefits/losses?

14. What comments do you have about the decision of Department B to cease any involvement in the WC course? What reasons do you have for your views?

\section{SLC Senior Staff Member Interview}

1. Please outline your memory of what led to the establishment of WC, from Commerce's first approaches to the SLC.

2. What was your response to Commerce's decision to make WC a compulsory course for all first year B.Com students? What impact did you see this decision having on your School?

3. What did you hope would be gained by your School/discipline through the launching of the course?

4. To what extent were these hopes realised? What are your reasons for your answer?

5. What comments do you have on the decision of Department B to cease any involvement in WC?

\footnotetext{
Appendix B: Learner Outcomes For Writing For Commerce By the end of this course you will:

1. have an introductory understanding of the communication process and how to apply it to reading and writing tasks in your commerce courses

2. understand and use active and critical reading skills for different academic tasks

3. have developed library research and referencing skills
} 
4. understand and apply the purpose, structure and organisation of explanatory, evaluative and argument essays in your commerce subjects, using appropriate register

5. understand and apply the purposes and structure of key grammatical forms used in the above genres of writing

6. know how to analyse essay and other assignment topics, test and exam questions

7. understand and apply processes and strategies of planning, organizing and editing for effective academic writing

8. be aware that university study necessitates the active and critical construction of knowledge by students

9. have experienced the benefits of group work for the development of your reading and writing abilities

10. have developed self-reflective skills and applied them to your own learning processes

\section{Appendix C: Example of a Short Writing Task}

Write TWO paragraphs of about TEN lines each, in which you:

Use the convergence model of communication to show how academic reading can be seen as the active negotiation of meaning (from many sources of meaning) between a writer and a reader of a text.

In your paragraphs, draw on relevant aspects of at least two of the following readings from your reader:

Fielding, M. 1993. The Process of Communication

Cleary, S. (Ed). 2003. Ch 4: Reading Skills

Jackson, F. 2000. Ways of Understanding The Reading Process

In your paragraphs make sure you:

provide a relevant main idea (controlling sentence)

define key terms, using your own words as far as possible

provide supporting details for the main idea in further sentences

link each supporting idea clearly back to the concept/s contained in your main idea

provide relevant supporting examples

pay attention to your choice of nouns and pronouns (e.g. you, she, he, it, they, one): make sure what you are referring to is very clearly $>$ signposted $=$ for your reader - too many pronouns on their own can get very confusing

reference all information taken from the prescribed reading - e.g.

Communication can be defined as

(Fielding, 1993:15)

\section{Before Writing:}

Analyse the topic above carefully (What specific information/concepts are you being asked to work with? I.E. identify the key CONTENT words. How are you being asked to work with those concepts? I.E. Identify the key DIRECTION words in the topic.)

Create some reading questions from your topic analysis to guide your reading and note making Make selective notes from each of the readings, taking down only information needed to answer your reading questions

Plan your paragraphs using a visual organiser such as a mind-map/spray diagram or a flow chart

\section{BIOGRAPHICAL NOTE}

Fiona Jackson lectures inter-cultural communication, sociolinguistics and academic literacy at the University of KwaZulu-Natal, Pietermaritzburg campus. She is a co-author of 'Exploring Our Voices: Effective English Teaching in Multilingual Classrooms’. Email: FJackson@ukzn.ac.za 